\title{
Early diagnosis of rheumatic diseases: an evaluation of the present situation and proposed changes
}

\author{
Brygida Kwiatkowska ${ }^{1}$, Filip Raciborski ${ }^{2}$, Anna Kłak ${ }^{3}$, Maria Maślińska' ${ }^{1}$, Jerzy Gryglewicz ${ }^{4}$ \\ ${ }^{1}$ Department of Early Arthritis, Institute of Rheumatology, Warsaw, Poland \\ ${ }^{2}$ Department of Epidemiology and Health Promotion, Institute of Rheumatology, Warsaw, Poland \\ ${ }^{3}$ Department of Prevention of Environmental Hazards and Allergology, Medical University of Warsaw, Poland \\ ${ }^{4}$ Postgraduate Education Centre, Łazarski University, Warsaw, Poland
}

\begin{abstract}
Musculoskeletal pain is a very common complaint, affecting $30-40 \%$ of the European population. It is estimated that approximately 400,000 Poles suffer from inflammatory rheumatic diseases, such as rheumatoid arthritis, ankylosing spondylitis and psoriatic arthritis, and a vast majority of those affected are working-age individuals. Patients with suspected arthritis require prompt diagnosis and treatment, as any delays may result in irreversible joint destruction and disability. Currently in Poland, the lag time between the onset of symptoms and diagnosis is, on average, as much as 35 weeks. In this paper, we review the current state of specialist rheumatology care in Poland and propose a reorganised care model that includes early diagnosis of inflammatory arthritis. The main goal we wish to achieve with our reorganised model is to enhance access to outpatient specialist rheumatology care for patients with suspected arthritis. We believe that our model should make it possible to considerably reduce the lag time between GP referral and the diagnosis and treatment by a rheumatologist to as little as 3 to 4 weeks. This article provides a proposal of changes that would achieve this goal and is a summary of the report published by the Institute of Rheumatology in September 2014.
\end{abstract}

Key words: arthritis, early diagnosis, proposed changes.

\section{Introduction}

Rheumatic diseases are a diverse group of conditions. The main focus of rheumatologists is on inflammatory arthritides, as opposed to non-inflammatory conditions, such as osteoarthritis (OA). The most common autoimmune rheumatic diseases include rheumatoid arthritis (RA), spondyloarthritides, such as ankylosing spondylitis (AS), psoriatic arthritis (PSA), and other systemic connective tissue diseases, such as systemic lupus erythematosus (SLE), systemic sclerosis (SSc) and Sjögren syndrome (SS) [1]. All these conditions share several common features: they are all chronic conditions, they all cause joint inflammation and destruction, and they may all involve internal organs, which is associated with progressive disability and may be the direct cause of death. Their ae- tiology is still not completely clear, and they cannot be effectively prevented. RA is the most prevalent and best understood rheumatic disease, and awareness of it in society is the highest among these diseases. It is estimated that the risk of RA is affected by genetic factors, which increase that risk by about 50-60\% [2]. Women are more commonly affected than men (with the male-to-female ratio being $3: 1$ ), and the mean age at diagnosis is between 30 and 50 years of age [3]. Population studies have shown that within 20 years of onset, $19 \%$ of patients with RA become completely disabled and 35\% die [4, 5].

\section{Epidemiological data}

Epidemiological data are not complete in Poland and are mostly derived from the statistics maintained by the

Address for correspondence:

Brygida Kwiatkowska, Early Arthritis Clinic, Institute of Rheumatology, Spartańska 1, 02-637 Warsaw, Poland,

e-mail: brygida.kwiatkowska@ir.ids.pl

Submitted: 07.01.2015, Accepted: 18.02.2015 
Social Insurance Institution (ZUS, Zakład Ubezpieczeń Spotecznych) and the National Health Fund (NFZ, Narodowy Fundusz Zdrowia). According to ZUS, in 2013 in Poland, diseases of the bones, joints, muscles and connective tissue resulted in more than 29.2 million days of sick absenteeism and were the fourth most common cause of sick leave. It is estimated that approximately 400,000 Poles suffer from inflammatory arthritides, with a vast majority of those affected being working-age individuals. According to the NFZ, in 2012, 1.2 million individuals were being treated for $\mathrm{OA}$, and as regards inflammatory arthritides, there were: 137,000 cases of RA; 6700 of juvenile idiopathic arthritis (JIA; M08, M09); 14,100 of psoriatic arthritis (L40.5, M07); 47,700 of other inflammatory arthritides (M13, M14); 30,700 of systemic connective tissue diseases (M30-M36); and 19,100 of spondylitis, such as ankylosing spondylitis and spondyloarthritis not otherwise specified (M45, M46, M49) [6]. In conclusion, according to the above data, 248,600 patients in 2012 received a diagnosis of an inflammatory rheumatic disease. A total of 145,000 hospitalisations for musculoskeletal and connective tissue diseases were recorded in 2012 in Poland among men (77.6 per 10,000 inhabitants) and 230,000 among women (115.6 per 10,000 inhabitants). Of the total of 374,000 patients hospitalised with the ICD-10 diagnoses of M00-M99, 40\% were aged between 45 to 64 years (16\% were aged $45-54$ years and $24 \%$ were aged $55-64$ years) and $28 \%$ were aged 65 years and older (32\% were aged up to 45 years) [7].

\section{Rheumatology patients in the Polish public healthcare system}

In a report published by the Institute of Rheumatology in 2014 the need for change to the current healthcare of patients with arthritis is highlighted. The report also presents the current state of knowledge about the diagnosis and the treatment of these patients in Poland [8]. According to the data presented in the report, currently in Poland the lag time between the onset of symptoms of arthritis and the establishment of diagnosis and initiation of treatment is, on average, as much as 35 weeks (8 to 9 months)! This is much longer than the maximum lag time recommended by the European standards. The available analyses show that the factor that most contributes to this delay is the lag time between the moment the patient sees his/her general practicioner (GP) and the time he/she is seen by a rheumatologist [9]. Appropriate medical intervention undertaken too late means longer persistence of inflammation, which may result in decreased efficacy of the treatment that is given at a later time. This also translates into deterioration of the quality of life and higher expenditure on the part of the payor (the use of more expensive treatments, lower chances of achieving rapid remission or of gradually decreasing the disease activity). The increased lag time to diagnosis also results from the fact that before they finally reach a rheumatologist, the patients are first referred to other specialists, such as orthopaedic surgeons, neurologists and physiatrists.

\section{Access to the system of specialist rheumatology care in Poland}

On the basis of the data presented in the NFZ registry in 2014, there were 709 outpatient rheumatology clinics contracted by the National Health Fund. According to the Polish Chamber of Physicians and Dentists (NIL, Naczelna Izba Lekarska), a total of 1808 rheumatologists were registered in Poland, 1633 of whom were practising rheumatologists (as of 30 June 2014). This means that, in statistical terms, there are slightly more than 4 rheumatologists in Poland per 100,000 inhabitants $[2,4]$. For comparison, the number of practising cardiologists is currently 3269 (8.5 per 100,000) [10]. The data on the number of practising rheumatologists in Poland do not fully reflect the actual situation. The mean age of rheumatologists in Poland is a considerable problem, as nearly a third of them are over 60 years of age $[11,12]$. According to the data published by the NFZ (as of 31 May 2014), the median waiting time for an outpatient appointment with a rheumatologist for stable cases in Poland is 28 days. For stable cases (which means patients without exacerbation of the disease) the median and average waiting time for hospitalisation in the rheumatologic ward in Poland is assessed respectively at 71 days (measured by median) and 182 days (measured by arithmetic mean). This considerable discrepancy is due to the occurrence of extreme cases. Out of the 80 rheumatology clinics, 4 reported a median waiting time exceeding 1300 days, i.e. more than 3.5 years! In nearly $10 \%$ of the rheumatology clinics patients have to wait for admission more than one year [13].

Given the above data, early diagnosis of rheumatic diseases gains particular significance. It is necessary to implement principles of management that point the patients in the direction of the right "diagnostic path". On the other hand, early recognition of a health problem and implementation of an optimal, effective treatment will make it possible to avoid such sequelae of inflammatory arthritides as disability, reduced productivity, and absenteeism. According to the EULAR recommendations of 2007, each patient with persistent joint swelling, even if only one joint is affected, should be referred to and examined by a rheumatologist within 6 weeks of the onset of symptoms [14], and treatment should 
be initiated within 12 weeks. In the context of early diagnosis, the term "therapeutic window" was therefore coined to refer to the period between the onset of symptoms and the establishment of diagnosis and the initiation of effective treatment. It has been adopted that the therapeutic window should not exceed the 12 weeks proposed by the EULAR [15]. As mentioned above, the mean lag time between the onset of symptoms and seeing a rheumatologist in Poland is as much as 35 weeks [9], and it is difficult to launch a discussion on maintaining in our current conditions close to the recommended 12 weeks.

In inflammatory arthritides, establishing the diagnosis and initiating the treatment within the therapeutic window increases the chances of remission. Early arthritis is diagnosed when at least one painful and swollen joint is present and the clinical presentation does not yet justify the diagnosis of RA, spondylarthritis or another inflammatory connective tissue disease. The diagnosis of early arthritis mandates the initiation of treatment with disease-modifying anti-inflammatory drugs (DMARDs). At this point the assessment of prognostic factors of aggressive disease is important, such as formation of erosions (detected on imaging) or high activity of inflammation (detected in laboratory tests). Methotrexate has been recognised as the drug of choice. In about $70 \%$ of patients with early arthritis, the implementation of effective treatment upon the diagnosis allows for remission that persists for up to 2 years [16].

In order to enable early diagnosis and to effectively shorten the lag time from the onset of symptoms to the diagnosis, it is necessary to reorganise the primary care system and the outpatient specialist care system. The report published by the Institute Rheumatology presents proposals for changes focusing on reducing the time from the initial visit to a GP to referral of the patient to a rheumatologist [8]. In the newly proposed system, each patient seeing his/her GP for symptoms of arthritis for the first time should be referred directly to a Centre for Early Diagnosis of Arthritis. Primary care physicians do not have the necessary competences or means to establish definite diagnoses of inflammatory arthritides, nor can they implement appropriate and effective treatment. In the early stage of the disease, GPS generally provide symptomatic treatment, which is not a good solution in the long run, as it delays the right diagnosis and initiation of DMARDs, thereby reducing the chances of achieving remission. Rapid access to rheumatologists could be possible if:

- specialist rheumatology outpatient Centres for Early Diagnosis of Arthritis were established,

- a system of fast-track referral of patients with early symptoms of arthritis was established, with GPs and other specialists being the doctors referring these patients to the rheumatologists,

- new pricing was established for outpatient specialist care procedures offered at early diagnostic facilities,

- a list was compiled of necessary procedures to be performed during appointments at early diagnostic facilities,

- patients diagnosed with early arthritis or early RA were closely monitored during the first year after diagnosis,

- patients managed at CEDEs were transferred to outpatient specialist care (outpatient rheumatology clinics) for further follow-up after the first year of observation [8].

\section{Centres for Early Diagnosis of Arthritis}

Centres for Early Diagnosis of Arthritis should be established within the framework of outpatient specialist care [8]. Opening of such facility by a healthcare establishment will be conditional upon satisfaction of specific requirements, such as the availability of appropriate staff (experienced rheumatologists) and appropriate facilities to perform all the diagnostic and therapeutic procedures during the scheduled visits (laboratory tests, imaging studies, administration of drugs via the parenteral and subcutaneous routes). An experienced rheumatologist is defined as a medical practitioner with at least 5 years of professional experience at an outpatient or inpatient rheumatology facility, and his or her knowledge and experience guarantee a correct diagnostic and therapeutic plan. According to this fast-track concept within the reorganised system of early diagnosis of rheumatic diseases, patients should be seen by a rheumatologist within 7 days of referral by their GPs (or other specialists). It is advisable that the patients arrive at the Centre for Early Diagnosis of Arthritis with the following basic test results: ESR, CRP, blood counts and urinalysis. The principal condition of referral would be pain and/ or swelling of at least one joint that is not caused by trauma. In the case of patients below 45 years of age, referral to a Centre for Early Diagnosis of Arthritis could additionally be justified by inflammatory spine pain, i.e. pain that is most severe during the second half of the night and in the morning, resolves or improves with movement during the day and may also be accompanied by buttock pain. If Centres for Early Diagnosis of Arthritis are to fulfil their roles, they should be able to perform the basic diagnostic procedures during the first 3 patient visits (visits 0 to 2); by this time most patients should have been provided with a final diagnosis and had their treatments initiated. This should be followed by four further appointments (visits 3 to 6), whose aim 


\section{VISIT 0}

History and physical examination of the joints carried out by an experienced rheumatologist

Diagnosis of inflammatory rheumatic disease confirmed - referral for further procedures

Diagnosis ruled out - patient referred back to GP with a feedback

\section{VISIT 1 (within 3 to 7 days after Visit 0 )}

Thorough history and physical examination of the joints

Laboratory tests: ESR, CRP, CBC with differential, AST, ALT, creatinine, uric acid, RF, ACPA, ANA 2 profile,

HLA-B27 (optionally)

Imaging studies: Chest X-ray (AP and lateral views), X-ray of the hands and feet, ultrasound of the affec-

ted hand or foot, MRI of the affected hand or foot (optionally), X-ray of the sacroiliac joints (optionally),

MRI of the sacroiliac joints (optionally)

\section{VISIT 2 (within 7 to 14 days after Visit 1 )}

Review of the lab and imaging results

Physical examination with the assessment of DAS 28 and, optionally, HAQ

Establishment of the final diagnosis and initiation of disease-modifying treatment

\section{VISIT 3 (3 months after Visit 2)}

Physical examination with the assessment of DAS 28 and, optionally, HAQ

Laboratory tests: ESR, CRP, CBC with differential, AST, ALT, creatinine, uric acid

Imaging studies (optionally): Ultrasound of the affected hand or foot

\section{VISIT 4 (6 months after Visit 2)}

Physical examination with the assessment of DAS 28 and, optionally, HAQ; and assessment of remission according to the ACR/EULAR criteria

Laboratory tests: ESR, CRP, CBC with differential, AST, ALT, creatinine

Imaging studies (optionally): Ultrasound of the affected hand or foot

\section{VISIT 5 (9 months after Visit 2)}

Physical examination with the assessment of DAS 28 and, optionally, HAQ Laboratory tests: ESR, CRP, CBC with differential, AST, ALT, creatinine Imaging studies (optionally): Ultrasound of the affected hand or foot

\section{VISIT 6 (12 months after Visit 2)}

Physical examination with the assessment of DAS 28 and, optionally, HAQ; and assessment of remission according to the ACR/EULAR criteria

Laboratory tests: ESR, CRP, CBC with differential, AST, ALT, creatinine, uric acid

Imaging studies: Chest X-ray (AP and lateral views), X-ray of

the hands and feet, ultrasound of the affected hand or foot, MRI of

the affected hand or foot (optionally), X-ray of the sacroiliac joints

(optionally), MRI of the sacroiliac joints (optionally)

\section{SUBSEQUENT VISITS EVERY 6 MONTHS (within the services of outpatient rheumatology clinics)}

Fig. 1. Diagram illustrating the management of new patients at Centres for Early Diagnosis of Arthritis. Source: the authors. Published with the consent of the management of the Institute of Rheumatology Warsaw [acc. 8]. 
would be to monitor treatment effects and, if necessary, to adjust the treatment (Fig. 1). These activities should yield a treatment plan optimally developed for the individual patient in order to achieve the maximum treatment effect in the form of disease remission.

By visit 6 each patient will have been given a final diagnosis and optimal treatment will have been selected. The patient should then be referred to the rheumatology clinic functioning within the outpatient specialist care system.

\section{Costs of the proposed changes}

The diagnosis of early arthritis not otherwise specified without magnetic resonance imaging (MRI) costs 757 zlotys, the diagnosis of RA with MRI costs 1232 zlotys, and the diagnosis of a spondyloarthropathy with MRI costs 1222 zlotys. According to the diagnostic criteria developed by the Assessment of SpondyloArthritis international Society (ASAS), MRI of sacroiliac joints is an important element in the diagnostic process. In the current system of specialist rheumatology care, while it is possible to perform all the investigations that would fall within the scope of early diagnosis, the way individual appointments have been priced in the outpatient setting requires the patient to complete 4 to 5 visits, which often causes a delay of up to one year between the diagnosis and initiation of appropriate treatment. The present state of affairs often forces unnecessary hospitalisations for diagnostic purposes, as then, after a mere 4 days of inpatient stay, the patient is discharged home with a complete set of investigations, a final diagnosis and a recommended treatment plan. Frequently, however, the time the patients have to wait before they are admitted to rheumatology wards greatly exceeds the therapeutic window (as illustrated above), and, additionally, this practice increases public expenditure on inpatient treatment. Another drawback of the current system is that it limits the access of other patients, those with already established diagnoses and severe disease, to inpatient treatment. This could be avoided due to early diagnosis, so that such patients could have rapid access to diagnostic and therapeutic procedures, and those who are more severely ill could obtain more rapid assistance in the inpatient setting.

\section{Conclusions}

The concept of changes in the area of early diagnosis of rheumatic diseases is consistent with the principles of the so-called 'queue scheme'. The main goal of the concept is to enhance access to outpatient specialist care for patients with suspected inflammatory arthritis. What is more, we have placed special emphasis on the establishment of fast-track referrals for new patients, i.e. patients who are seen by a rheumatologist for the first time. The reorganised model presented in the cited report would require Centres for Early Diagnosis of Arthritis to be established within the existing system of outpatient specialist care, the tasks of which would be to carry out rapid and comprehensive diagnostic evaluation of new patients. If the diagnosis of an inflammatory arthritis was confirmed, the patient would also be prescribed appropriate effective treatment. The principal goal of the proposed change is to create a system that would enable the final diagnosis to be established and treatment to be initiated within 12 weeks after the onset of symptoms. According to our concept, each individual in whom their GP (or another specialist) suspects an inflammatory arthritis should be referred to a Centre for Early Diagnosis of Arthritis as soon as possible. The patient's GP would not be required to order additional tests, as these would be carried out by the Centre. This would save the time and money for tests that would otherwise have to be repeated anyway. Within 7 days of referral the patient would be admitted to the nearest Centre for Early Diagnosis of Arthritis. Preliminary diagnosis would be established during the first visit to the Centre. In cases of OA, the patients would be provided with detailed information on their health and transferred back under the care of their GP (who should be provided with instructions on further management). Osteoarthritis need not be managed within the framework of specialist care. If during the first appointment a preliminary diagnosis of inflammatory arthritis is established, the patient would be referred for further tests and treatment should be initiated as soon as possible. This stage should be completed within 2 to 3 weeks of the first appointment at the Centre for Early Diagnosis of Arthritis. For the next 12 months the patient would remain under the care of the Centre for treatment monitoring and optimisation, and would then be transferred under the care of an outpatient rheumatology facility. The proposed solution would make it possible to reduce the number of patients waiting for an appointment at rheumatology clinics. Patients with OA would be referred to their GPS, which would increase the accessibility of specialist services in rheumatology to patients with inflammatory arthritides. What is more, the proposed solution would reduce the requirement for diagnostic investigations in the inpatient setting. According to preliminary calculations, the cost of 7 visits to a Centre for Early Diagnosis of Arthritis (including ultrasound and MRI) is comparable with the cost of a single hospitalisation at a rheumatology ward reconciled within DRG H87D (68 points, i.e. 3536 zlotys at the moment). Polish rheumatologists have been fighting for years for the establishment of a system of 
early diagnosis of arthritis. The justifiability of such solutions is beyond any doubt. As Prof Witold Tłustochowicz, National Consultant in Rheumatology, has pointed out in his review of the report, investing 105 million zlotys in early diagnosis of rheumatic diseases would enable $10 \%$ of the current expenditure on disability allowance to be saved. Pioneering projects are under way in many facilities in Poland, the aim of which is to establish centres for early diagnosis. One such project is the "Programme for the early detection of arthritis" implemented by the Department of Rheumatology and Systemic Connective Tissue Diseases at Dr Jan Biziel Memorial University Hospital No. 2, Bydgoszcz, Poland. These projects are, however, local in nature and do not affect in any way the whole of the rheumatology care in Poland. A systemic change is required to meet the increasing needs in the setting of limited resources.

\section{Acknowledgements}

We would like to thank Danuta Kapołka, MD, PhD, Bogdan Batko, MD, PhD, and Sławomir Jeka, MD, PhD, Assistant Professor, for their help with collection of data, which has enabled us to estimate the average costs of procedures in the proposed system of early diagnosis in Poland. We would also like to thank all the other individuals who have contributed to this report and those who have put in great effort over the past years to create a system of early diagnosis of rheumatic diseases in Poland. Their efforts have been an inspiration for us.

The article has been based, upon the permission of the Eleonora Reicher Institute of Rheumatology in Warsaw, and is a summary of the report entitled "Wczesna diagnostyka chorób reumatycznych - ocena obecnej sytuacji i rekomendacje zmian" published by this Institute.

The authors declare no conflict of interest.

\section{References}

1. Decker JL. American Rheumatism Association nomenclature and classification of arthritis and rheumatism (1983). Arthritis Rheum 1983; 26: 1029-1032.

2. Tobón GJ, Youinou P, Saraux A. The environment, geo-epidemiology, and autoimmune disease: Rheumatoid arthritis. J Autoimmun 2010; 35: 10-14.

3. Invernizzi P, Miozzo M, Selmi C, et al. X chromosome monosomy: a common mechanism for autoimmune diseases. J Immunol 2005; 175: 575-578.

4. Scott DL, Symmons DP, Coulton BL, Popert AJ. Long-term outcome of treating rheumatoid arthritis: results after 20 years. Lancet 1987; 239: 1108-1111.
5. Humphreys JH, Warner A, Chipping J, et al. Mortality trends in patients with early rheumatoid arthritis over 20 years: Results from the Norfolk Arthritis Register. Arthritis Care Res (Hoboken) 2014; 66: 1296-1301.

6. Śliwczyński A. Epidemiologia zapalnych chorób stawów w Polsce. 32. Konferencja Ordynatorów i Kierowników Poradni Reumatologicznych (23-24 maja 2013). Warszawa 2013. Conference materials.

7. Narodowy Instytut Zdrowia Publicznego Państwowy Zakład Higieny. Chorobowość szpitalna - średnia długość pobytu w dniach [Accessed on: 19.04.2014] http://www.statystyka. medstat.waw.pl/wyniki/Tabela52012.htm.

8. Kwiatkowska B, Raciborski F, Maślińska M, et al. Wczesna diagnostyka chorób reumatycznych - ocena obecnej sytuacji i rekomendacje zmian. Instytut Reumatologii im. prof. dr hab. med. Eleonory Reicher, Warszawa 2014.

9. Raza K, Stack R, Kumar K, et al. Delays in assessment of patients with rheumatoid arthritis: variations across Europe. Ann Rheum Dis 2011; 70: 1822-1825.

10. [Online] http://www.nil.org.pl/rejestry/centralny-rejestr-lekarzy/ informacje-statystyczne [Accessed on: 19.04.2014].

11. [Online] http://www.ereumatologia.pl/Prof-Witold-Tlustochowiczpowolajmy-siec-szybkiej-diagnostyki-w-zapaleniu-stawow, 9851.html [Accessed on: 19.04.2014].

12. Drapała A, Grabowska-Woźniak E, Gryglewicz J, et al. Stan opieki reumatologicznej w Polsce - streszczenie raportu projektu badawczego. Oficyna Wydawnicza Uczelni Łazarskiego, Warszawa 2011.

13. [Online] http://kolejki.nfz.gov.pl/ [Accessed on: 19.04.2014].

14. Combe B, Landewe R, Lukas C, et al. EULAR recommendations for the management of early arthritis: report of a task force of the European Standing Committee for International Clinical Studies Including Therapeutics (ESCISIT). Ann Rheum Dis 2007; 66: 34-45.

15. Raza K, Saber TP, Kvien TK, et al. Timing the therapeutic window of opportunity in early rheumatoid arthritis: proposal for definitions of disease duration in clinical trials. Ann Rheum Dis 2012; 71: 1921-1923.

16. Van Eijk IC, Nielen MM, Van der Horst-Bruinsma I, et al. Aggressive therapy in patients with early arthritis results in similar outcome compared with conventional care: the STREAM randomized trial. Rheumatology 2012; 51: 686-694. 